\title{
How to define an area where transmission of arthropod-borne disease is occurring?
}

D Domanovic (Dragoslav.Domanovic@ecdc.europa.eu) ${ }^{1}$, J Giesecke ${ }^{1}$

1. European Centre for Disease Prevention and Control (ECDC), Stockholm, Sweden

Citation style for this article:

Domanovic D, Giesecke J. How to define an area where transmission of arthropod-borne disease is occurring?. Euro Surveill. 2012;17(20):pii=20171. Available online: http://www.eurosurveillance.org/ViewArticle.aspx?Articleld=20171

In this issue of Eurosurveillance, the authors of the report Epidemiological surveillance of West Nile neuroinvasive disease in Italy, 2008 to 2011 use one of various definitions of 'affected area' that are utilised in practice [1].

In connection with the planning of measures to maintain the safety of the blood supply during the outbreaks of West Nile fever in Member States of the European Union (EU), we became aware that several different terms and definitions are in use to describe the same status of the infection risk in an area, and that these terms often vary by disease. This creates difficulties in establishing criteria for geographical deferral of blood donors, points to discrepancies in terminology between professional guidelines and European legislation [2] and raises questions about the applicability of existing terminology in outbreaks of other arthropodborne diseases (ABD).

Hence, we propose a simple but structured and common terminology for areas where an ABD is occurring. It is based on the analytical revision of terms and definitions and intended to be used mainly for the implementation of measures maintaining safety and sustainability of the supply with substances of human origin.
The key point in the proposal is that every area where the chances of transmission of an ABD to humans are higher than nil is factually a risk area. This statement does not measure the level of the risk. The actual risk level in an area depends on environmental conditions, the presence of arthropod vectors and pathogen, previous $A B D$ transmission to humans, and the disease's seasonal recurrence in the area. Consequently, we propose the following terminology and classification of risk areas (Table):

A risk area is an area where individuals are exposed to the risk (which can be small or large) of being infected with a locally acquired ABD. This is a generalised use of the term 'risk area' in order to prevent the imprecision linked to this term due to its use to signify a specific level of risk in an area.

A predisposed area is a risk area where existing conditions might facilitate the transmission of an ABD to humans, but the respective pathogen has not been detected.

Conditions favouring transmission are receptivity and/ or vulnerability of the area. The receptivity of an area is the presence and/or spread of arthropod vectors and the existence of other ecological and climatic factors

TABLE

Terminology and classification of the risk areas where an arthropod-borne disease is occurring

\begin{tabular}{|c|c|c|c|c|}
\hline \multirow{2}{*}{ Risk area type } & \multicolumn{4}{|c|}{ Criteria } \\
\hline & Conditions $^{\mathrm{a}}$ & Pathogen $^{b}$ & Transmission $^{c}$ & Recurrence $^{d}$ \\
\hline Predisposed & + & - & - & - \\
\hline Affected & + & + & + & - \\
\hline Endemic & + & + & + & + \\
\hline
\end{tabular}

a Environmental conditions favouring transmission of arthropod-borne diseases to human.

b Presence of the pathogen in vectors and/or animals.

'Transmission of arthropod-borne diseases to human

d Seasonal recurrences of arthropod-borne disease transmissions to human. 
favouring ABD transmission to humans [3]. The vulnerability of an area means the proximity to areas where this $A B D$ infection is present or a frequent influx of infected individuals or groups and/or infective arthropods [3].

An imperilled area is a risk area where the pathogen has been detected in vectors, or transmission of the pathogen to animals has been detected, or the transmission of the pathogen to humans has occurred previously in a defined period, specific for each ABD.

An affected area is a risk area with ongoing transmission of an ABD to humans. This means that at least one case of transmission of autochthonous $A B D$ to a human has been confirmed in the area according to the agreed, standardised and disease-specific case definition [4]. Under exceptional circumstances, a probable case can be used to determine transmission but only in specific and agreed situations when case confirmation cannot be performed within a reasonable time.

An endemic area is a risk area where transmission of an $A B D$ to humans is taking place over several seasonal cycles, the number of which may be different for different ABDs.

Once declared, the risk area remains within the same or moves to a higher risk type throughout the current season of the vector's activity. The risk for ABD transmission to humans in an area should be re-evaluated for every season of a given vector's activity.

In addition to assigning a risk, an area must be accurately determined geographically, i.e. with name, location and boundaries. This should follow the biological and epidemiological findings (surveillance of human and animal cases, field investigation etc.) but be adapted to the administrative territorial divisions in order to allow epidemiological mapping and harmonisation and to avoid misunderstanding and imprecision. In an initial rapid risk assessment, broader administrative divisions should be applied cautiously to avoid unnecessary donor deferrals. The final geographical determination of an area where a vector-borne disease is present is possible after an epidemiological analysis and risk assessment have been performed. For practical reasons, simplification may be necessary regarding travel advice as well as for donors of substances of human origin returning from the area of exposure.

The proposed system is a framework for classifying an area according to the present risk and other characteristics of disease transmission to humans. The epidemiological characteristics required for the classification should be determined for every ABD individually (e.g. number of seasonal cycles for the definition of an endemic area).

Although a clear terminology is important for implementation of the appropriate public health or other precautionary measures, these should be selected only after a thorough risk assessment and risk/benefit analysis. The applied measures should be proportional to the level of risk and implemented in a timely fashion [5].

\section{Acknowledgments}

We thank the following people from ECDC for their comments on the manuscript: Laurence Marrama-Rakotoarivony, Wim Van Bortel, Eva Warns-Petit, Herve Zeller, Gianfranco Spiteri and Bruno Ciancio.

References

1. Rizzo C, Salcuni P, Nicoletti L, Ciufolini MG, Russo F, Masala R, et al. Epidemiological surveillance of West Nile neuroinvasive diseases in Italy, 2008 to 2011. Euro Surveill. 2012;17(20):pii=20172. Available from: http://www. eurosurveillance.org/ViewArticle.aspx?Articleld=20172

2. Commission Directive 2004/33/EC of 22 March 2004 implementing Directive 2002/98/EC of the European Parliament and of the Council as regards certain technical requirements for blood and blood components. Official Journal of the European Union. L 91. Luxembourg: Publications Office of the European Union; 30 Mar.2004. Available from: http:// eur-lex.europa.eu/LexUriServ/LexUriServ.do?uri=0J:L:2004:09 1:0025:0039:EN:PDF

3. Global Malaria Programme. Malaria elimination: a field manual for low and moderate endemic countries. Geneva: World health Organization; 2007. ISBN 9789241596084 . Available from: http://www.rbm.who.int/toolbox/tool_EliminationManualWHO. html

4. COMMISSION DECISION of 17 July 2003 amending Decision No 2119/98/EC of the European Parliament and of the Council and Decision 2000/96/EC as regards communicable diseases listed in those decisions and amending Decision 2002/253/ EC as regards the case definitions for communicable diseases. . Official Journal of the European Union.L 184/35. Luxembourg: Publications Office of the European Union; 23 Jul 2003. Available from: http://eur-lex.europa.eu/LexUriServ/ LexUriServ.do?uri=0J:L:2003:184:0035:0039:EN:PDF.

5. European Directorate for the Quality of Medicines \& HealthCare (EDQM). Guide to the preparation, use and quality assurance of blood components. Recommendation No. R (95) 15. 16th ed. Strasbourg: Council of Europe; 2010. Available from: http:// www.centronazionalesangue.it/sites/default/files/guida edqm_16_edizione.pdf 